\title{
Retrofit of Mass-Exchange Networks with Superstructure-Based MINLP Formulation
}

\author{
Cheng-Liang Chen* and Ping-Sung Hung \\ Department of Chemical Engineering, National Taiwan University, Taipei 10617, Taiwan, ROC
}

\begin{abstract}
This paper presents a simultaneous optimization method for the retrofit of existing massexchange networks (MENs). A mixed-integer nonlinear programming (MINLP) model is formulated on the basis of a stage-wise superstructure representation for the MENs. The MINLP formulation simultaneously considers the costs of mass separating agents, the reassignment of existing exchange units to different process stream matches and their need for additional tray numbers, column height, or both, and the creation and installation of new units. Several examples from the literatures are supplied to demonstrate the applicability of the proposed MENs retrofit model.
\end{abstract}

\section{Introduction}

There are many indispensable mass-exchange operations used in chemical industries, such as absorption, stripping, extraction, adsorption, and ion exchange. ${ }^{1}$ The development of a systematic integration of massexchange units for assigned separating tasks to maximize the overall plant profit results in the massexchange network synthesis problem. In contrast with the grass-roots design for an existing mass-exchange network and given the new stream conditions for rich process flows, lean mass separation agents (MSAs), or both, the retrofit problem is the determination of the optimally redesigned network structure that features the minimum total modification cost.

Until recently, compared to the burgeoning investigations on the synthesis, retrofit, or both of heat-exchange networks (HENs), not many research reports have been presented to address the integration of mass-exchange networks (MENs) or a systematic redesign strategy, though the design of an individual mass-exchange unit is a well-established topic. In early development, a systematic two-staged procedure for the synthesis of cost-effective MENs was first proposed by El-Halwagi and Manousiouthakis. ${ }^{2}$ Therein, the pinch point that limits the extent of mass transfer between the rich streams and MSAs is identified, and a preliminary network is generated to feature the maximum mass exchange in the first stage of synthesis. The preliminary network is then improved in the second stage to develop a final cost-efficient configuration to satisfy the assigned exchange obligations. Thereafter, a linear trans-shipment model is established for automatic synthesis of MENs with a single-component target. ${ }^{3}$ This work is further extended in a later report to include networks for regeneration of recyclable lean streams. ${ }^{4}$ Hallale and Fraser $^{5-8}$ also presented a method, in a series of papers, for targeting the capital cost, as well as the operating cost, of a mass exchange network, and these costs are further combined to give the total annual cost target. The design of MENs to meet the targets is also discussed in detail. These papers demonstrate that, contrary to previous belief, using the minimum number of units

* To whom correspondence should be addressed. Tel: 886 2-23636194. Fax: 886-2-23623040.E-mail: CCL@ntu.edu.tw. does not necessarily lead to a minimum cost design. ${ }^{5}$ In contrast to previous works that simplify the problem by decomposition on the basis of the concept of pinch points, a hyperstructure-based representation for MENs is proposed by Papalexandri et al. ${ }^{9}$ Therein, the synthesis task for MENs is formulated as a mixed-integer nonlinear programming problem with both network operating and investment costs being optimized simultaneously. The impact of simultaneously minimizing operating and investment costs to waste minimization problems are demonstrated via several examples.

All of the above-mentioned works, however, have mainly been aimed at grass-root designs for massexchange networks. Lately, Fraser and Hallale ${ }^{10}$ applied the pinch technology approach ${ }^{11}$ for the retrofit of HENs to retrofitting MENs. The mathematical programming approach for the MENs retrofit is, however, not yet developed. On the basis of many successful extensions of HENs approaches to grass-root MENs design, this article explores the postulate that the approach used in the retrofit of HENs may be successfully applied to the retrofit of MENs.

Tjoe and Linnhoff ${ }^{11}$ proposed the retrofit of HENs design by applying the pinch technology. It is a twostage method using targeting procedures to choose the project scope. Ciric and Floudas ${ }^{12}$ proposed an MINLP model for the HENs retrofit that is based on a generalized match-network hyperstructure. Yee and Grossmann ${ }^{13}$ developed a two-step approach, which used their assignment trans-shipment model in the first step to search the promising retrofit structures at different energy recovery levels. In the second step, the optimization stage, an optimal retrofit design was obtained through the construction of a superstructure and the optimization of its MINLP model. Ma et al. ${ }^{14}$ also proposed an MINLP model for HENs retrofit. The model simultaneously considers the tradeoff between the reduction of utility use and the costs for structural modification and additional tray numbers, column heights or both on the basis of stagewise superstructures. This paper is motivated to present an optimization approach to retrofit MENs. The proposed stagewise superstructure ${ }^{15,16}$ based the representation for MENs retrofit is analogous to the one introduced by $\mathrm{Ma}$ et al. ${ }^{14}$ for the retrofitting of HENs. The proposed model simultaneously considers the operating cost for external 


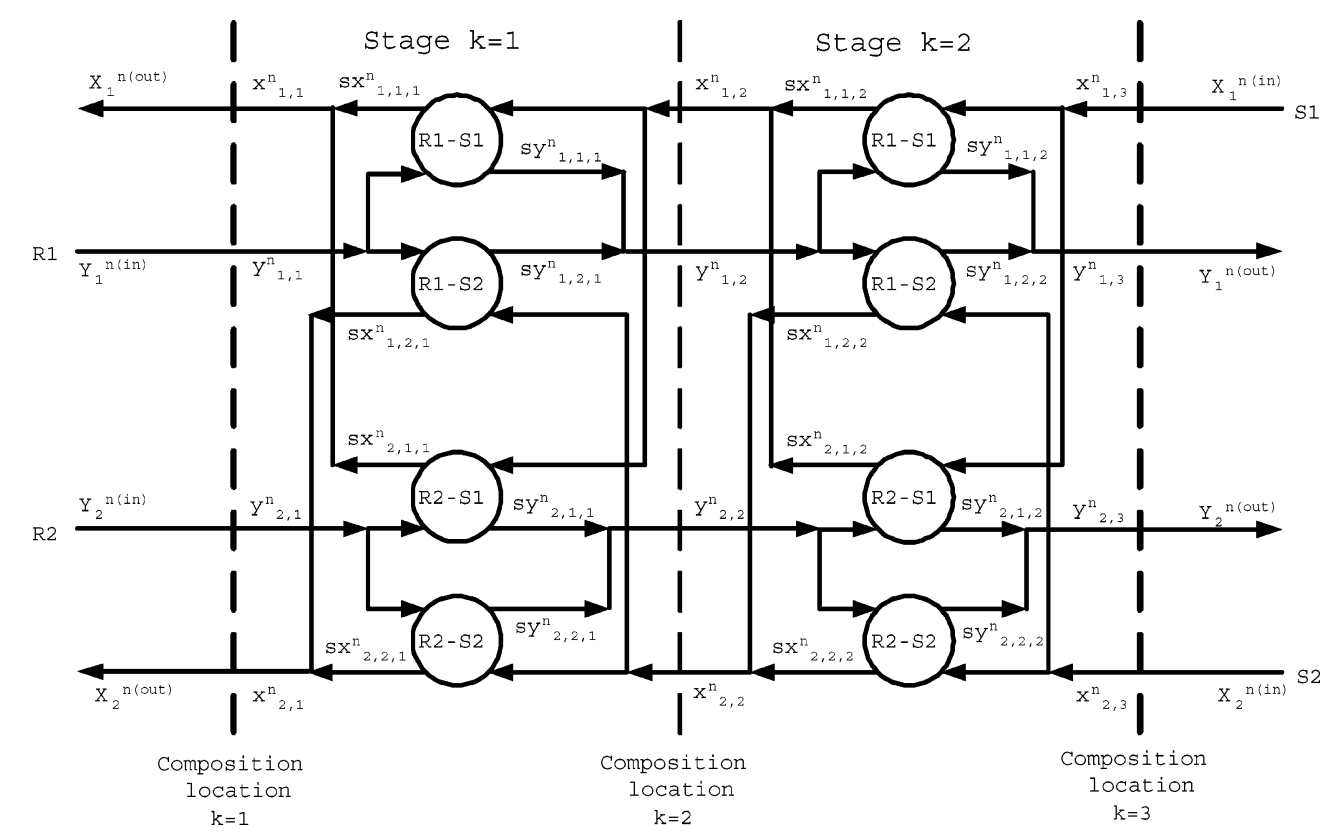

Figure 1. A two-stage superstructure for retrofitting a mass-exchange network with two rich and two lean streams.

mass separating agents, the mass-exchange unit reassignment cost, the additional tray/height cost, the new mass-exchange unit installation cost, etc. Several examples from literature will be used to demonstrate the efficiency of the proposed MENs retrofit model.

\section{Problem Statement}

The retrofit of a mass-exchange network problem addressed in this paper can be stated similar to that for retrofitting heat-exchanger networks, ${ }^{12}$ as follows. Given is an existing MEN including a set of $N$ exchange units of known size; a set $i \in \mathbf{R P}$ of rich process streams with fixed flow rates, $G_{i}$, in which some transferable components $n \in \mathbf{T C}$ are to be removed; compositions of rich streams at input $Y_{i}^{n(\text { in) }}$, output $Y_{i}^{n \text { (out) }}$, and their upper limits $Y_{i}^{n(\text { up) }}$; a set $j \in \mathbf{L P}$ of lean process streams with maximal available rates, $L_{j}$, for removing those transferable components in rich streams, and their input, output/upper compositions, $X_{j}^{n \text { (in) }}, X_{j}^{n \text { (out) }} / X_{j}^{n \text { (up) }}$; an equilibrium relation, $y_{i}^{n *}=f_{i j}^{n}\left(x_{j}^{n}\right)$, for the distribution of transferable components between all rich and lean streams, where $y_{i}^{n *}$ and $x_{j}^{n}$ are equilibrium compositions of component $n$ in the $i$ th rich and the $j$ th lean streams, respectively, and a minimum composition approach, $\epsilon_{i j}^{n}$. The objective is to determine the optimally redesigned MEN that features the minimum total modification cost. The issues considered in the MEN retrofit include the costs of mass separating agents, the costs for reassignment of existing exchange units, and the cost for additional tray numbers, column heights, or both, and the cost for purchase and installation of new units. Other costs such as repiping are neglected in the formulation.

Several assumptions are also made to simplify the MENs retrofit problem, including 9 (1) the mass flow rates of all streams remain constant throughout the network (i.e., only small composition changes take place or the mass exchange is carried out through counter diffusion), (2) the equilibrium relationship of each component does not depend on the other components and the equilibrium relationships are linear in the range of compositions involved, (3) the mass exchange units are of the counter-current type, (4) no mass exchange between rich streams is allowed (i.e., the possibility of different rich streams mixing is excluded), (5) heat integration between streams is not allowed, (6) the network operates under constant pressure, (7) all the systems have the same column diameters and thus the cost of each column is proportional to their tray number and height, and (8) pumping and piping costs can be neglected.

\section{Model Formulation}

A stagewise superstructure for considering all possible matches between rich and lean streams in a massexchange network synthesis problem, analogous to the superstructure for heat-exchange network synthesis, is presented for MEN retrofit. ${ }^{16}$ Figure 1 shows a twostage superstructure for a MEN synthesis problem with two rich and two lean streams. The relevant indices/ sets and parameters/variables are defined in the Nomenclature. The objective for the MEN retrofit and all constraints that should be considered are stated in the following.

Overall Mass Balance for Transferable Components over the Whole Network. An overall mass balance is needed to ensure sufficient exchange of all transferred components for all rich streams. The constraints specify that the overall mass transferable requirement of each rich stream for each component, $n$, must be equal to the sum of the $n$th component which is exchanged with other lean process streams or MSAs at each stage. Similar constraints also apply for all lean streams, as stated in the following

$$
\begin{aligned}
& \left(y_{i 1}^{n}-y_{i}^{n},_{N_{S}+1}\right) G_{i}=\sum_{\forall k \in \mathbf{S} \mathbf{T} \forall j \in \mathbf{L} \mathbf{P}} \sum_{i j k}^{n} \forall i \in \mathbf{R P}, n \in \mathbf{T C} \\
& \left(x_{j 1}^{n}-x_{j}^{n},_{N_{S}+1}\right) L_{j}=\sum_{\forall k \in \mathbf{S T} \forall i \in \mathbf{R} \mathbf{P}} \sum_{i j k}^{n} \forall j \in \mathbf{L P}, n \in \mathbf{T C}
\end{aligned}
$$

Mass Balance in Each Stage. A mass balance is also needed in each stage for each stream to determine the composition of each transferable component, $n$, as 
well as the partition of flow rates for all parallel units. For a superstructure with $N_{\mathrm{S}}$ stages, $N_{\mathrm{S}}+1$ levels of composition are involved. Note that the index $k$ is used to represent the stage and the composition location in the superstructure. For both cases, stage or composition location $k=1$ involves the highest compositions. The component and total mass balance for each stream in each stage $k$ are as follows, where $M_{i j k}^{n}$ denotes the transferred composition $n$ between rich stream $i$ and lean stream $j$ in stage $k$.

$$
\begin{aligned}
\left(y_{i k}^{n}-y_{i, k+1}^{n}\right) G_{i} & =\sum_{\forall j \in \mathbf{L} \mathbf{P}} M_{i j k}^{n} \forall i \in \mathbf{R P}, k \in \mathbf{S T}, n \in \mathbf{T C} \\
\left(x_{j k}^{n}-x_{j, k+1}^{n}\right) L_{j} & =\sum_{\forall i \in \mathbf{R} \mathbf{P}} M_{i j k}^{n} \forall j \in \mathbf{L P}, k \in \mathbf{S T}, n \in \mathbf{T C}
\end{aligned}
$$

Mass Balance in Each Exchange Unit. For the exchange unit between rich stream $i$ and lean stream $j$ in stage $k$, the compositions before mixers, $s y_{i j k}^{n}$ and $s x_{i j k}^{n}$, are defined. A component mass balance is needed for each local exchange unit, where $g_{i j k}$ and $l_{i j k}$ are split mass flow rates.

$$
\begin{gathered}
g_{i j k}\left(y_{i k}^{n}-s y_{i j k}^{n}\right)= \\
M_{i j k}^{n} \forall i \in \mathbf{R P}, j \in \mathbf{L P}, k \in \mathbf{S T}, n \in \mathbf{T C} \\
l_{i j k}\left(s x_{i j k}^{n}-x_{j, k+1}^{n}\right)= \\
M_{i j k}^{n} \forall i \in \mathbf{R P}, j \in \mathbf{L P}, k \in \mathbf{S T}, n \in \mathbf{T C}(3)
\end{gathered}
$$

The total mass balances for these split mass flow rates in each stage $k$ can also be stated as in the following

$$
\begin{gathered}
\sum_{\forall j \in \mathbf{L} \mathbf{P}} g_{i j k}=G_{i} \forall i \in \mathbf{R P}, k \in \mathbf{S T} \\
\sum_{\forall i \in \mathbf{R} \mathbf{P}} L_{i j k}=L_{j} \forall j \in \mathbf{L P}, k \in \mathbf{S T}
\end{gathered}
$$

Notice that the balance equations around all mixers from the split streams are not necessary because these equations are redundant to eqs. 2 and $3 .{ }^{17}$

Assignment of Superstructure Inlet/Outlet Compositions. The given inlet/outlet compositions of the rich and lean process streams are assigned as the inlet/ outlet compositions to the superstructure. For rich streams, the superstructure inlet corresponds to composition location $k=1$, while for lean streams, the inlet corresponds to location $k=N_{\mathrm{S}}+1$

$$
\begin{gathered}
Y_{i}^{n(\text { in })}=y_{i 1}^{n} \quad Y_{i}^{n(\text { out })}=y_{i}^{n},_{N_{S}+1} \quad \forall i \in \mathbf{R P}, n \in \mathbf{T C} \\
X_{j}^{n(\text { in })}=x_{j}^{n},_{N_{S}+1} \quad X_{j}^{n(\text { out })}=x_{j 1}^{n} \quad \forall j \in \mathbf{R P}, n \in \mathbf{T C}
\end{gathered}
$$

Feasibility of the Transferable Components. Constraints are also needed to guarantee monotonic decrease of all compositions at successive stages.

$$
\begin{aligned}
& y_{i k}^{n} \geq y_{i, k+1}^{n} \quad \forall i \in \mathbf{R P}, k \in \mathbf{S T}, n \in \mathbf{T C} \\
& x_{j k}^{n} \geq x_{j, k+1}^{n} \quad \forall j \in \mathbf{L P}, k \in \mathbf{S T}, n \in \mathbf{T C}
\end{aligned}
$$

Logical Constraints for Transferable Components. Logical constraints and binary variables, $z_{i j k}$, are needed to determine the existence or absence of stream matches $(i, j)$ in stage $k$. An integer value of 1 for binary variable $z_{i j k}$ designates that the match between rich stream $i$ and lean stream $j$ in stage $k$ is present in the optimal network. $z_{i j k}$ is zero if the match $(i, j)$ in stage $k$ is absent, and thus the mass load $M_{i j k}^{n}$ also becomes zero. The constraints for mass loads, $M_{i j k}^{n}$, are as follows where $U$ is a large positive upper bound.

$$
\begin{gathered}
M_{i j k}^{n}-U z_{i j k} \leq 0 \quad \forall i \in \mathbf{R P}, j \in \mathbf{L P}, k \in \mathbf{S T}, n \in \mathbf{T C} \\
z_{i j k} \in\{0,1\}
\end{gathered}
$$

Feasibility Constraints of the Equilibrium Relationships. Let $d y x i_{i j k}^{n}$ and $d y x o_{i j k}^{n}$, respectively, denote the composition approaches in the lean and rich ends of the mass exchanger between rich stream $i$ and lean stream $j$ in stage $k$. The following equilibrium relationships guarantee that the required minimum driving force, $m_{i j}^{n} \epsilon_{i j}^{n}$, around the mass exchanger should this unit exist, (i.e., $z_{i j k}=1$ ) will be overcome. These constraints are automatically relaxed if $z_{i j k}=0$. The details of these relations can be found in Appendix A.

$$
\begin{gathered}
d y x i_{i j k}^{n}, d y x o_{i j k}^{n} \geq m_{i j}^{n} \epsilon_{i j}^{n} \\
\forall i \in \mathbf{R P}, j \in \mathbf{L P}, k \in \mathbf{S T}, n \in \mathbf{T C} \\
d y x i_{i j k}^{n} \leq y_{i k}^{n}-m_{i j}^{n} s x_{i j k}^{n}-b_{i j}^{n}+\Gamma\left(1-z_{i j k}\right) \\
\forall i \in \mathbf{R P}, j \in \mathbf{L P}, k \in \mathbf{S T}, n \in \mathbf{T C} \\
d y x o_{i j k}^{n} \leq s y_{i j k}^{n}-m_{i j}^{n} x_{j, k+1}^{n}-b_{i j}^{n}+\Gamma\left(1-z_{i j k}\right) \\
\forall i \in \mathbf{R P}, j \in \mathbf{L P}, k \in \mathbf{S T}, n \in \mathbf{T C}
\end{gathered}
$$

Constraints for Existing Match Reassignment. Let $E_{p}$ denote the set of existing matches and $w_{i j k}^{o p q}=1$ if the existing stream match $(o, p)$ in stage $q$ is reassigned as a new stream match $(i, j)$ in stage $k$. Then for each existing unit in $E_{p}$, at most one new application can be reassigned, as follows

$$
\sum_{\forall k \in \mathbf{S} \mathbf{T}} \sum_{\forall j \in \mathbf{L} \mathbf{P}} \sum_{\forall i \in \mathbf{R} \mathbf{P}} w_{i j k}^{o p q} \leq 1 \quad \forall(o, p, q) \in E_{p}
$$

Constraints for Installing New Exchangers. One of the major objectives of the MEN retrofit is the full utilization of existing exchange units. Thus, some of the required exchange units in the redesigned MEN might come from the reassignment of existing ones. New massexchange units can be distinguished by eq 10 , where $z_{i j k}^{\text {(new) }}=1$ denotes the stream match $(i, j)$ in stage $k$ which needs a new purchased unit.

$$
z_{i j k}^{(\text {new })}=z_{i j k}-\sum_{(o, p, q) \in E_{p}} w_{i j k}^{o p q} \quad \forall i \in \mathbf{R P}, j \in \mathbf{L P}, k \in \mathbf{S T}
$$

Required Size Determination. The sizing equations for the mass transfer units are defined in detail in Appendix B. Two sizing formulas are given below for 
the tray column and the packed tower, respectively, for stream match $(i, j)$ in stage $k$.

$$
N_{i j k} \geq\left[\frac{\left(y_{i k}^{n}-s y_{i j k}^{n}\right)^{0.3275}+\left(s y_{i j k}^{n^{*}}-y_{i j, k+1}^{n^{*}}\right)^{0.3275}}{\left(d y x i_{i j k}^{n}\right)^{0.3275}+\left(d y x o_{i j k}^{n}\right)^{0.3275}}\right]^{1 / 0.3275}
$$

$\forall i \in \mathbf{R P}, j \in \mathbf{L P}^{t}, k \in \mathbf{S T}, n \in \mathbf{T C}$ for tray column

$$
H_{i j k} \geq \frac{M_{i j k}^{n}}{K_{y}^{n} a S\left[\frac{\left(d y x i_{i j k}^{n}\right)^{0.3275}+\left(d y x o_{i j k}^{n}\right)^{0.3275}}{2}\right]^{1 / 0.3275}}
$$

$\forall i \in \mathbf{R P}, j \in \mathbf{L} \mathbf{P}^{(h)}, k \in \mathbf{S T}, n \in \mathbf{T C}$

for packed tower

Additional Stage Numbers or Column Height for Reassigned Units. As stated before, some units in the retrofit network can be reassigned from existing ones. All existing stages $N_{o p q}^{\text {(exist) }}$ or column height $H_{o p q}^{\text {(exist) }}$ can thus be used directly to proceed the desired task.

$$
\begin{aligned}
N_{i j k}^{(\text {reassign })} & \leq \sum_{(o, p, q) \in E_{P}} w_{i j k}^{o p q} N_{o p q}^{\text {(exist) }} \\
\forall i \in \mathbf{R P}, j \in \mathbf{L P} & \mathbf{P}^{(\mathrm{t})}, k \in \mathbf{S T} \text { for tray column } \\
H_{i j k}^{\text {(reassign) }} & \leq \sum_{(o, p, q) \in E_{p}} w_{i j k}^{o p q} H_{o p q}^{\text {(exist) }} \\
\forall i \in \mathbf{R P}, j \in \mathbf{L P} &
\end{aligned}
$$

For those units reassigned from existing ones, surplus stages or column height will be ignored. However, additional stage numbers $N_{i j k}^{\text {(add) }}$ or column height $H_{i j k}^{\text {(add) }}$ should be appended to provide desired separation performance for those units where the reassigned stage numbers or column height are less than the required values.

$$
\begin{aligned}
& N_{i j k}^{(\text {add) }} \geq N_{i j k}-N_{i j k}^{(\text {reassign })} \\
& \quad \forall i \in \mathbf{R P}, j \in \mathbf{L P} \mathbf{P}^{(\mathrm{t})}, k \in \mathbf{S T} \text { for tray column } \\
& H_{i j k}^{(\text {add) }} \geq H_{i j k}-H_{i j k}^{\text {(reassign) }} \\
& \quad \forall i \in \mathbf{R P}, j \in \mathbf{L} \mathbf{P}^{(\mathrm{h})}, k \in \mathbf{S T} \text { for packed tower }
\end{aligned}
$$

Bounds on Variables. Bounds are set on the mass flow rate of the lean streams and their final compositions and also on the final compositions of rich streams when they are not fixed.

$$
\begin{array}{r}
L_{j} \leq L_{j}^{\text {(up) }} \quad x_{j 1}^{n} \leq X_{j}^{n(\text { up })} \quad \forall j \in \mathbf{L P}, n \in \mathbf{T C} \\
y_{i, N_{S}+1}^{n} \leq Y_{i}^{n \text { (up) }} \quad \forall i \in \mathbf{R P}, n \in \mathbf{T C}
\end{array}
$$

Optional Constraints. Some additional constraints such as no stream splits, forbidden matches, and required or restricted matches can be easily included in this model. For example, the stream splitting can be prevented by constraining the number of matches for split streams in each stage, such as

$$
\begin{gathered}
\sum_{\forall i \in \mathbf{R} \mathbf{P}} z_{i j k} \leq 1 \quad \forall j \in \mathbf{L P}, k \in \mathbf{S T} \\
\sum_{\forall j \in \mathbf{L} \mathbf{P}} z_{i j k} \leq 1 \quad \forall i \in \mathbf{R P}, k \in \mathbf{S T}
\end{gathered}
$$

The maximum total number of mass exchange units can be limited by adding an upper bound for selected exchangers, by the following constraint

$$
\sum_{\forall i \in \mathbf{R} P} \sum_{\forall j \in \mathbf{L} \mathbf{P}} \sum_{\forall k \in \mathbf{S T}} z_{i j k} \leq \mathrm{MEU}
$$

Other restrictions can also be considered by assigning suitable values for specific integer variables. For example, if the match between rich stream $i=1$ and lean stream $j=2$ is not allowable, then one can assign $z_{12 k}$ $=0 \forall k \in \mathbf{S T}$.

Objective Function. The objective function of the proposed model simultaneously includes (1) the cost of mass separating agents, (2) the cost of purchasing and installing new exchangers, (3) the cost of reassigning existing exchangers at different matches, and (4) the cost of purchasing additional stages or column height for existing exchangers. Without loss of generality, the cost of repiping streams is assumed negligible, such as stated in the following, where $x$ and $\Omega$ denote the design variables and the feasible space defined by all constraints, eqs 1-14. CAF is the capital annulisation factor, which is set as 1 in the retrofit problems.

$$
\begin{aligned}
& \min _{\boldsymbol{x} \in \Omega} J=\sum_{\forall j \in \mathbf{L} \mathbf{P}} \mathrm{AC}_{j} \times L_{j} \quad \text { MSAs cost } \\
& +\sum_{\forall i \in \mathbf{R P}} \sum_{\forall j \in \mathbf{L P}} \sum_{\forall k \in \mathbf{S T}} \operatorname{CAF}\left[\left(\sum_{\forall(o, p, q) \in E_{p}} C_{i j k}^{o p q} w_{i j k}^{o p q}\right)+\right. \\
& \left.C_{i j k}^{(\text {inst) }} z_{i j k}^{(\text {new })}\right] \text { fixed reassign and new unit cost } \\
& +\sum_{\forall i \in \mathbf{R} \mathbf{P}} \sum_{\forall k \in \mathbf{S T}} \mathrm{CAF}\left[\sum_{\forall j \in \mathbf{L} \mathbf{P}^{t}} C_{i j k}^{(\mathrm{t})} N_{i j k}^{(\mathrm{add})}+\right. \\
& \left.\sum_{\forall j \in \mathbf{L} \mathbf{P}^{(h)}} C_{i j k}^{(\mathrm{h})} H_{i j k}^{(\text {add })}\right] \quad \text { additional stage/height cost }
\end{aligned}
$$

\section{Numerical Examples}

Several examples adapted from El-Halwagi and Manousiouthakis ${ }^{2,3}$ and Papalexandri et al. ${ }^{9}$ are supplied to demonstrate the applicability of the proposed model to MEN retrofit problems. Notably, a $1 \mathrm{~m}$ column diameter for all tray columns, packed towers, or both has been assumed in this work. Thus the investment cost is proportional to the tray number or tower height only. The capital annualization factor is taken to be unity. For solving the MINLP formulation for the MEN retrofit model, the General Algebraic Modeling System ${ }^{18}$ is used as the main solution tool. The MINLP and NLP solvers are SBB and SNOPT, respectively.

4.1. Example 1: Retrofit of Coke-Oven Gas Sweetening Process. The coke-oven gas sweetening process, adapted from El-Halwagi and Manousiouthakis, ${ }^{2}$ is supplied to illustrate the proposed approach to the retrofit problems. The objective of the coke-oven gas (COG) sweetening is removal of hydrogen sulfide, $\mathrm{H}_{2} \mathrm{~S}$, from COG. The $\mathrm{H}_{2} \mathrm{~S}$ should be removed when the $\mathrm{COG}$ is used as a fuel to reduce the emission of corrosive $\mathrm{SO}_{2}$. The presence of ammonia in COG leads to the utilization of aqueous ammonia as a process lean stream, $S_{1}$. The chilled methanol is used as an external MSA, $S_{2}$, if the supply of aqueous ammonia is limited. The purification of COG involves washing the sour COG with sufficient aqueous ammonia and chilled methanol to absorb the required amounts of $\mathrm{H}_{2} \mathrm{~S}$. The acid gases are then stripped from the solvents and the regenerated MSAs are recirculated. The stripped acid gases are fed to a Claus unit, where the sulfur is recovered from $\mathrm{H}_{2} \mathrm{~S}$. The 


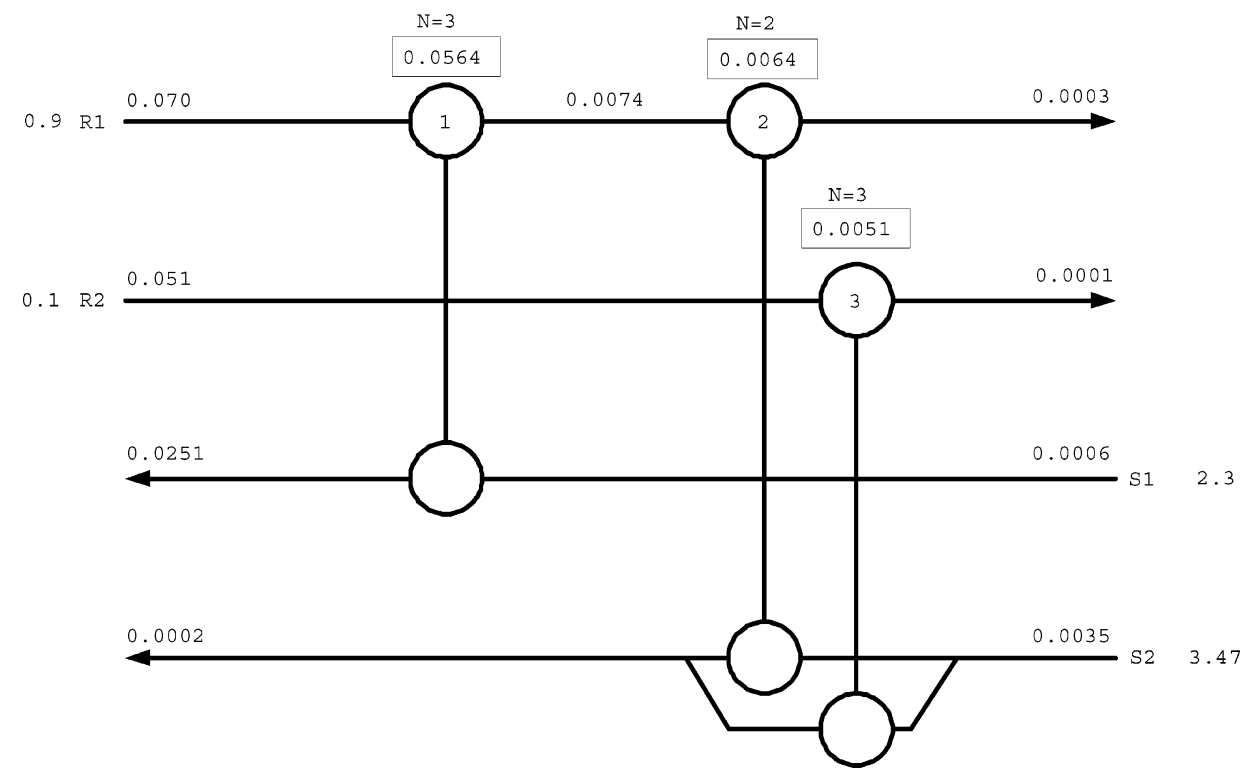

Figure 2. Grass-roots MEN design for COG example by Papalexandri et al. (1994).

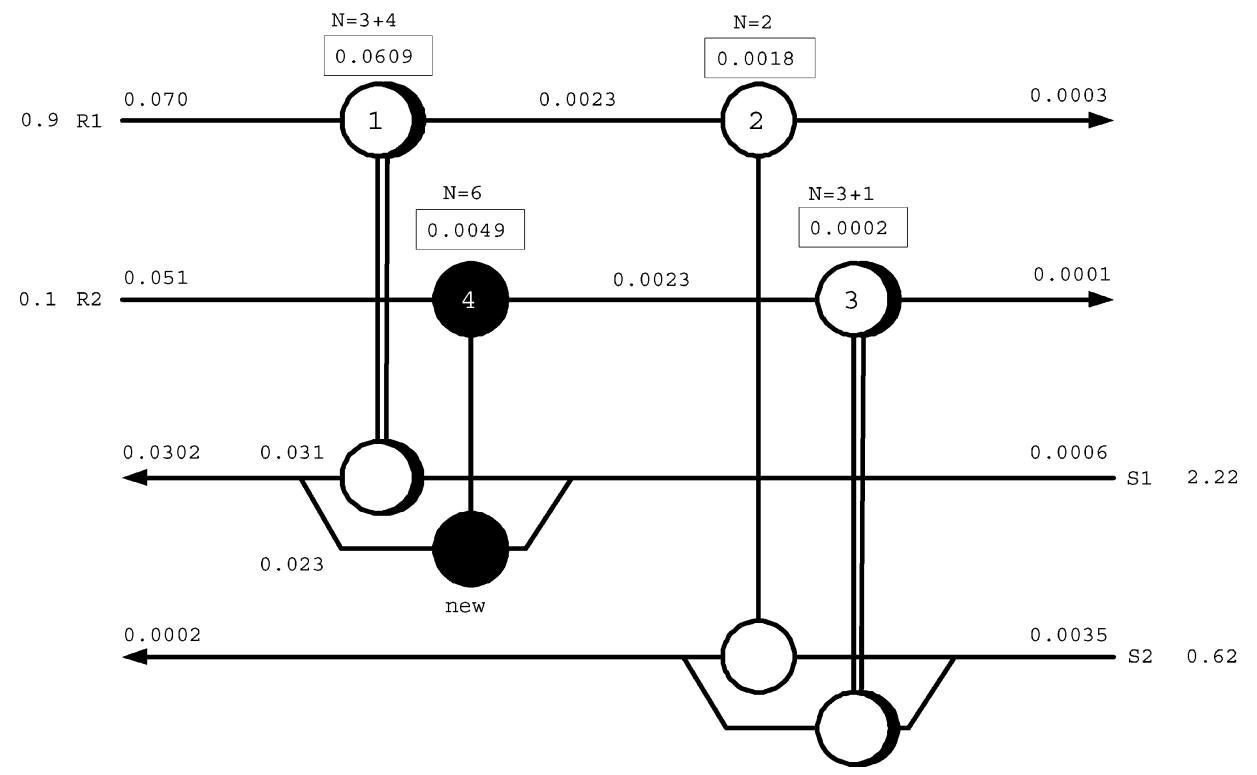

Figure 3. Retrofit design for COG example by Fraser and Hallale (2000e).

tail gases, leaving the Claus unit, ought to be treated for partial removal of unrecovered $\mathrm{H}_{2} \mathrm{~S}$. For a comparison purpose, the stream data modified by Papalexandri et al. ${ }^{9}$ for a more balanced distribution of annual investment and operational costs are adopted, as shown in Table 1. The equilibrium solubility data for $\mathrm{H}_{2} \mathrm{~S}$ in aqueous ammonia (with subscript 1) and methanol (subscript 2) can be respectively correlated by the following relationships

$$
\begin{gathered}
y=1.45 x_{1} \quad\left(\text { for } \mathrm{H}_{2} \mathrm{~S} \text { in aqueous ammonia }\right) \\
y=0.26 x_{2} \quad\left(\text { for } \mathrm{H}_{2} \mathrm{~S} \text { in methanol }\right)
\end{gathered}
$$

The mass-exchange units used are all Perforated-plate columns costing $\$ 4552$ per stage per year with a 5 year annualization. ${ }^{9}$ Therefore, it is $\$ 22760$ per equilibrium stage. A minimum composition difference of $\epsilon=0.0001$ is selected to determine the feasible mass exchange at the inlet and outlet of each potential mass-exchange unit. Figure 2 is the grass-roots design suggested by

\begin{tabular}{|c|c|c|c|c|c|c|}
\hline \multirow{2}{*}{\multicolumn{2}{|c|}{ rich streams }} & \multirow{2}{*}{\multicolumn{2}{|c|}{ description }} & \multirow{2}{*}{$\begin{array}{c}G_{i} \\
(\mathrm{~kg} / \mathrm{s})\end{array}$} & \multicolumn{2}{|c|}{ mass fraction } \\
\hline & & & & & $\bar{Y}_{i}^{(\text {in) }}$ & $Y_{i}^{\text {(up) }}$ \\
\hline \multirow{2}{*}{\multicolumn{2}{|c|}{$\begin{array}{l}R_{1} \\
R_{2}\end{array}$}} & \multirow{2}{*}{\multicolumn{2}{|c|}{$\begin{array}{l}\text { COG } \\
\text { tail gases }\end{array}$}} & 0.9 & 0.070 & 0.0003 \\
\hline & & & & 0.1 & 0.051 & 0.0001 \\
\hline \multirow[b]{2}{*}{ MSAs } & \multirow{2}{*}{\multicolumn{2}{|c|}{ description }} & \multirow{2}{*}{$\begin{array}{c}L_{j}^{\text {(up) }} \\
(\mathrm{kg} / \mathrm{s})\end{array}$} & \multicolumn{2}{|c|}{ mass fraction } & \multirow{2}{*}{$\begin{array}{c}\text { ann. cost } \\
(\$ \mathrm{~s} / \mathrm{kg} \mathrm{yr})\end{array}$} \\
\hline & & & & $X_{j}^{(\text {in })}$ & $X_{j}^{\text {(up) }}$ & \\
\hline$S_{1}$ & \multirow{2}{*}{\multicolumn{2}{|c|}{$\begin{array}{l}\text { aq. } \mathrm{NH}_{3} \\
\text { methanol }\end{array}$}} & 2.3 & 0.0006 & 0.0310 & 117360 \\
\hline$S_{2}$ & & & $\infty$ & 0.0002 & 0.0035 & 176040 \\
\hline
\end{tabular}

Table 1. Stream Data for COG example

Papalexandri et al. ${ }^{9}$ via hyperstructure-based optimization, and Figure 3 is the retrofit network proposed by Fraser and Hallale ${ }^{10}$ on the basis of pinch technology. The match connected with double lines denotes an existing unit with additional stages. A black bullet represents a new unit. The tray numbers or column heights are listed on the figure, and the mass load of each exchange unit is boxed. The streamflow rates and compositions are also depicted. In the Fraser-andHallale retrofit MEN, units 1 and 3 should be appended 
7194 Ind. Eng. Chem. Res., Vol. 44, No. 18, 2005

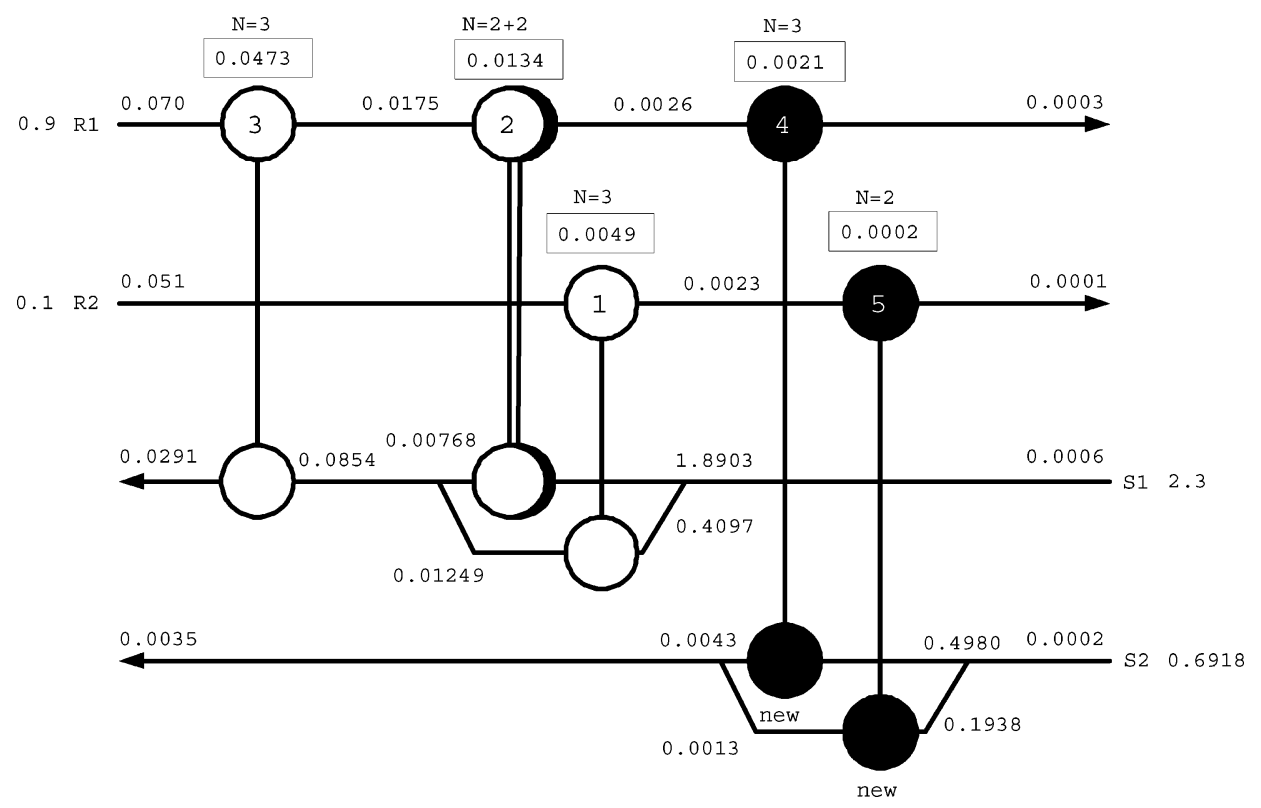

Figure 4. Proposed retrofit network for COG example without considering fixed reassignment cost and fixed installation cost.

with four and one stages, respectively, and the new unit 4 with six stages should be purchased. The proposed MINLP formulation is employed to determine the optimal retrofit for the COG example. The minimum number of superstructure stages, $N_{\mathrm{S}}$, is first set as max$\left\{N_{\mathrm{R}}, N_{\mathrm{L}}\right\}+1=3 .{ }^{14}$ The corresponding MINLP formulation involves 161 constraints and 251 variables of which 48 are binary. To compare with the retrofit result of Fraser and Hallale, ${ }^{10}$ we first consider cost of annual operating utilities and the additional numbers of tray stages or column heights for the retrofit. The resulting retrofit network is shown in Figure 4 with a minimum objective value of $\$ 551033$ for the first year, which includes the operating cost of $\$ 391713$ per year and the total capital cost for network modification of $\$ 159320$ in the first year. The annual saved operating cost is $\$ 881463-\$ 391713=\$ 489715$, hence the resulting payback is only $159320 / 489715=0.33$ year or 4 months. By comparing Figure 4 with Figure 3, no modification is required for units 1 and 3 , but unit 2 needs two additional stages. Two new units with three and two stages, respectively, are also required. The main reason is that the current objective function only considers annual operating cost and additional stage cost, the installation cost for new units is not taken into account. Notice that the current retrofit MEN has $N_{\mathrm{S}}$ $=3$ stages. Thus, the above retrofit procedure should be repeated again with additional superstructure stages, $N_{\mathrm{S}}=4$. The retrofit task can latter be stopped as one additional superstructure stage results in the same retrofit MEN.

4.2. Example 2: Retrofit of Coke-Oven Gas Sweetening Process with Multicomponent Targets. Example 1 is now extended to illustrate the proposed model for handling the retrofit problem with multiple contaminants. ${ }^{2}$ Carbon dioxide $\left(\mathrm{CO}_{2}\right)$ often occurs in COG with relatively large concentrations. Although it is not generally necessary to remove $\mathrm{CO}_{2}$ from $\mathrm{COG}$, partial removal is sometimes desirable to improve the heating value, and complete $\mathrm{CO}_{2}$ elimination is required for gases undergoing processing at very low temperatures, for example, in COG purification to provide hydrogen for ammonia synthesis. In this example, El-
Halwagi and Manousiouthakis ${ }^{2}$ considered the case where the inlet concentration of $\mathrm{CO}_{2}$ in $\mathrm{COG}$ is 6.0 $\mathrm{wt} / \mathrm{wt} \%$, and its desirable target composition is 0.5 wt/wt \%. $\mathrm{CO}_{2}$ also represents a major impurity in the Claus tail gases. For environmental protection purposes, it is desired to reduce the $\mathrm{CO}_{2}$ in the Claus off-gas from 11.5 to 1.0 (wt/wt \%). Over the range of operating conditions of interest, the equilibrium solubility data for $\mathrm{CO}_{2}$ in aqueous ammonia and methanol can be expressed as

$$
\begin{gathered}
y_{1}=1.45 x_{11} \quad\left(\text { for } \mathrm{H}_{2} \mathrm{~S} \text { in aqueous ammonia }\right) \\
y_{1}=0.26 x_{12} \quad\left(\text { for } \mathrm{H}_{2} \mathrm{~S} \text { in methanol }\right) \\
y_{2}=0.35 x_{21} \quad\left(\text { for } \mathrm{CO}_{2} \text { in aqueous ammonia }\right) \\
y_{2}=0.58 x_{22} \quad\left(\text { for } \mathrm{CO}_{2} \text { in methanol }\right)
\end{gathered}
$$

Suppose the cost for the reassignment of mass-exchange units and the installation cost for new mass-exchange units are included in the retrofit design objective, as shown in eq 19, where the reassignment cost and the installation cost are given as $C_{i j k}^{o p q}=\$ 45520$ for all $o \neq$ $i, p \neq j$, or both and $C_{i j k}^{(\mathrm{inst})}=\$ 91040$. The minimum number of superstructure stages, $N_{\mathrm{S}}$, is also set to be 3 at first. The corresponding MINLP formulation involves 269 constraints and 327 variables of which 48 are binary. Then the new objective value will become $\$ 670581$, which includes the annual operating cost of $\$ 374701$ and the total investment cost of $\$ 295880$ for the retrofit. The saved annual operating cost is $\$ 881463$ $-\$ 374701=\$ 506762$, hence the resulting payback is $295880 / 506762=0.58$ year or 7 months. The final retrofit network is shown in Figure 5. Notice that one new unit with seven stages is required. All of the abovementioned data has been reported in Table 2. When taking the reassignment cost and the installation cost into account, the network structure will be less one new unit than Figure 4, where the installation cost of a new unit is not considered in the latter case. It is noted that only two structural stages are applied for the resulting 


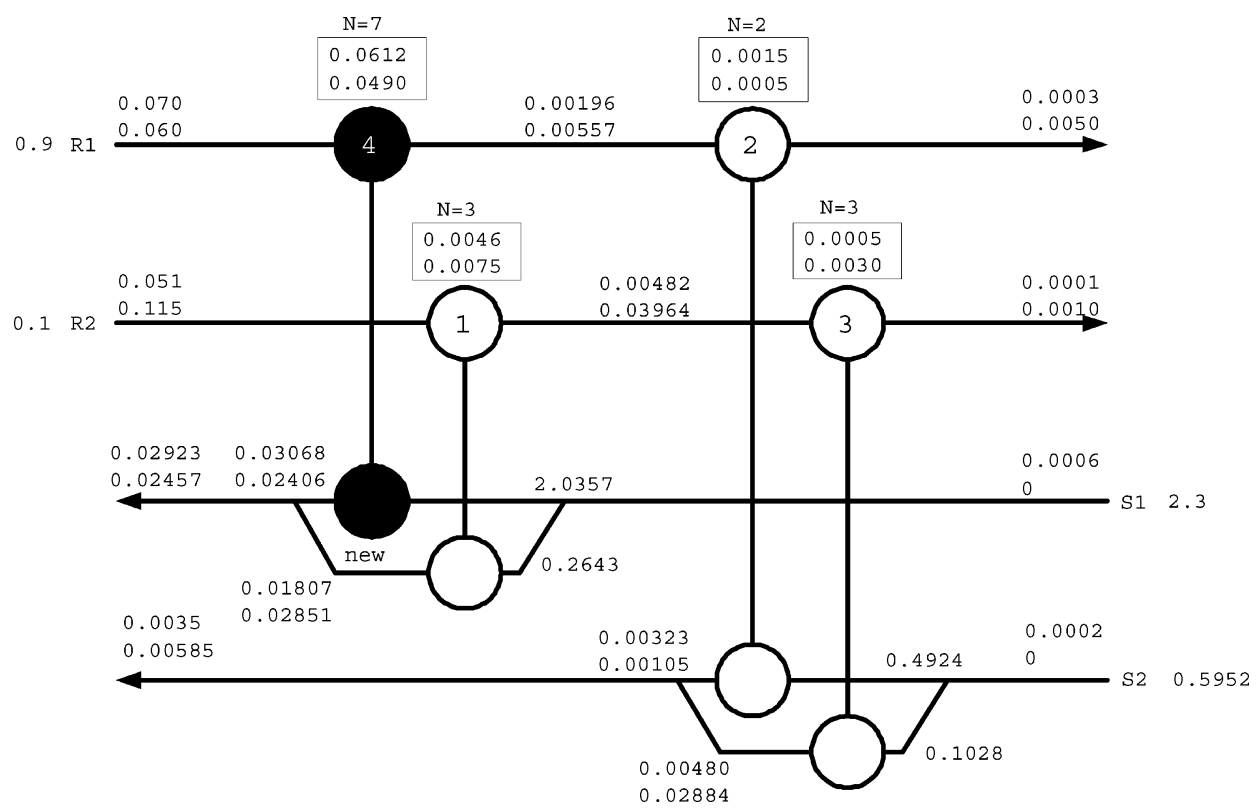

Figure 5. Proposed retrofit network for multicomponent COG example considering fixed reassignment and installation cost.

Table 2. Summary and Comparison of Total Modification Costs on the Basis of Pinch Technology and the Proposed MINLP Formulation for Examples 1 and 2

\begin{tabular}{|c|c|c|c|c|c|}
\hline & & total modification cost & annual operating cost & capital investment cost & saved operating cost \\
\hline \multirow[t]{2}{*}{1} & pinch design & 620044 & 371833 & 250360 & 509630 \\
\hline & MINLP approach & 551033 & 391713 & 159320 & 489715 \\
\hline \multirow[t]{2}{*}{2} & pinch design & - & - & - & - \\
\hline & MINLP approach & 670581 & 374701 & 295880 & 506762 \\
\hline
\end{tabular}

Table 3. Stream Data for Copper Recovery Example

\begin{tabular}{|c|c|c|c|c|c|c|}
\hline \multirow{2}{*}{\multicolumn{2}{|c|}{ rich stream }} & \multirow{2}{*}{\multicolumn{2}{|c|}{ description }} & \multirow{2}{*}{$\begin{array}{c}G_{i} \\
(\mathrm{~kg} / \mathrm{s})\end{array}$} & \multicolumn{2}{|c|}{ mass fraction } \\
\hline & & & & & $Y_{i}^{(\mathrm{in})}$ & $Y_{i}^{\text {(up) }}$ \\
\hline \multirow{2}{*}{\multicolumn{2}{|c|}{$\begin{array}{l}R_{1} \\
R_{2}\end{array}$}} & \multirow{2}{*}{\multicolumn{2}{|c|}{$\begin{array}{l}\text { ammon. soln } \\
\text { rinsewater }\end{array}$}} & 0.25 & 0.13 & 0.10 \\
\hline & & & & 0.10 & 0.06 & 0.02 \\
\hline \multirow[b]{2}{*}{ MASs } & \multirow{2}{*}{\multicolumn{2}{|c|}{ description }} & & \multicolumn{2}{|c|}{ mass fraction } & \multirow[b]{2}{*}{ annual cost } \\
\hline & & & $(\mathrm{kg} / \mathrm{s})$ & $X_{j}^{(\text {in) }}$ & $X_{j}^{\text {(up) }}$ & \\
\hline$S_{1}$ & \multicolumn{2}{|c|}{ LIX63 } & $\infty$ & 0.03 & 0.07 & 58,680 \\
\hline$S_{2}$ & \multicolumn{2}{|c|}{$P_{1}$} & $\infty$ & 0.001 & 0.02 & 704,160 \\
\hline
\end{tabular}

network. Thus, the repeated trial for MEN retrofit does not need to proceed with additional superstructure stages.

4.3. Example 3: Retrofit of Copper Recovery in An Etching Plant. This example, studied by ElHalwagi and Manousiouthakis, ${ }^{3}$ involves the removal of a single component, the copper, from an ammoniacal etching solution and a rinsewater stream. The etching of copper is achieved through ammoniacal solution, where the etching efficiency is higher for copper compositions between 10 and $13 \mathrm{wt} / \mathrm{wt} \%$. The copper contaminant is continuously removed from the ammoniacal solution, $R_{1}$, via solvent extraction, and the regenerated etchant is returned to the etching line. Meanwhile, the etched printed circuit boards are washed out with water, and the effluent rinse water, $R_{2}$, is also decontaminated by extraction and then recycled to the rinse vessel. A schematic representation of the etching process can be found in El-Halwagi and Manousiouthakis. $^{3}$

Two external MSAs are available for removal of copper: LIX63 (an aliphatic $\alpha$-hydroxyoxime, $S_{1}$ ) and $P_{1}$ (an aromatic $\beta$-hydroxyoxime, $S_{2}$ ). The cost data listed in Table 3 come from Papalexandri et al. ${ }^{9}$ Suppose that the mass transfers of copper are governed by the following linear equilibrium relationships, where $y$ and $x$ denote the weight percent of copper in the rich and lean streams, respectively ${ }^{3}$

$$
\begin{aligned}
& \left(R_{1}, S_{1}\right): y_{1}=0.734 x_{1}+0.001 \\
& \left(R_{2}, S_{1}\right): y_{2}=0.734 x_{1}+0.001 \\
& \left(R_{1}, S_{2}\right): y_{1}=0.111 x_{2}+0.008 \\
& \left(R_{2}, S_{2}\right): y_{2}=0.148 x_{2}+0.013
\end{aligned}
$$

The minimum number of superstructure stages, $N_{\mathrm{S}}$, is set to be 3 for the first trial. ${ }^{14}$ The corresponding MINLP formulation involves 160 constraints and 215 variables of which 30 are binary. The $K_{y} a$ values are $0.685 \mathrm{~kg}$ of copper $\mathrm{m}^{-3} / \mathrm{s}$ for $R_{1}$ and $0.211 \mathrm{~kg}$ of copper $\mathrm{m}^{-3} / \mathrm{s}$ for $R_{2} .{ }^{8}$ A minimum composition difference of $\epsilon=0.0007$ determines the feasible mass exchange at the inlet and outlet of all potential mass-exchange units.

Figure 6 is the grass-root design by Hallale and Fraser. ${ }^{8}$ Now suppose all of the rich streamflow rates will be increased four times that of the original values because of market variations (i.e., $G_{1}=4 \times 0.25=1.0$ $\mathrm{kg} / \mathrm{s}$ and $G_{2}=4 \times 0.1=0.4 \mathrm{~kg} / \mathrm{s}$ ). The retrofit network is shown in Figure 7 with a minimum objective value of $\$ 148805$ for the first year, which includes the operating cost of $\$ 125351$ per year and the total capital cost for network modification of $\$ 23454$ at the first year. By comparing Figure 7 with Figure 6, it is found that only unit 3 should be upgraded with additional 1.105 $\mathrm{m}$ in height. It is noted that only two structural stages are applied for the resulting network. Thus, the repeated trial for MEN retrofit does not need to proceed with additional superstructure stages. 
7196 Ind. Eng. Chem. Res., Vol. 44, No. 18, 2005

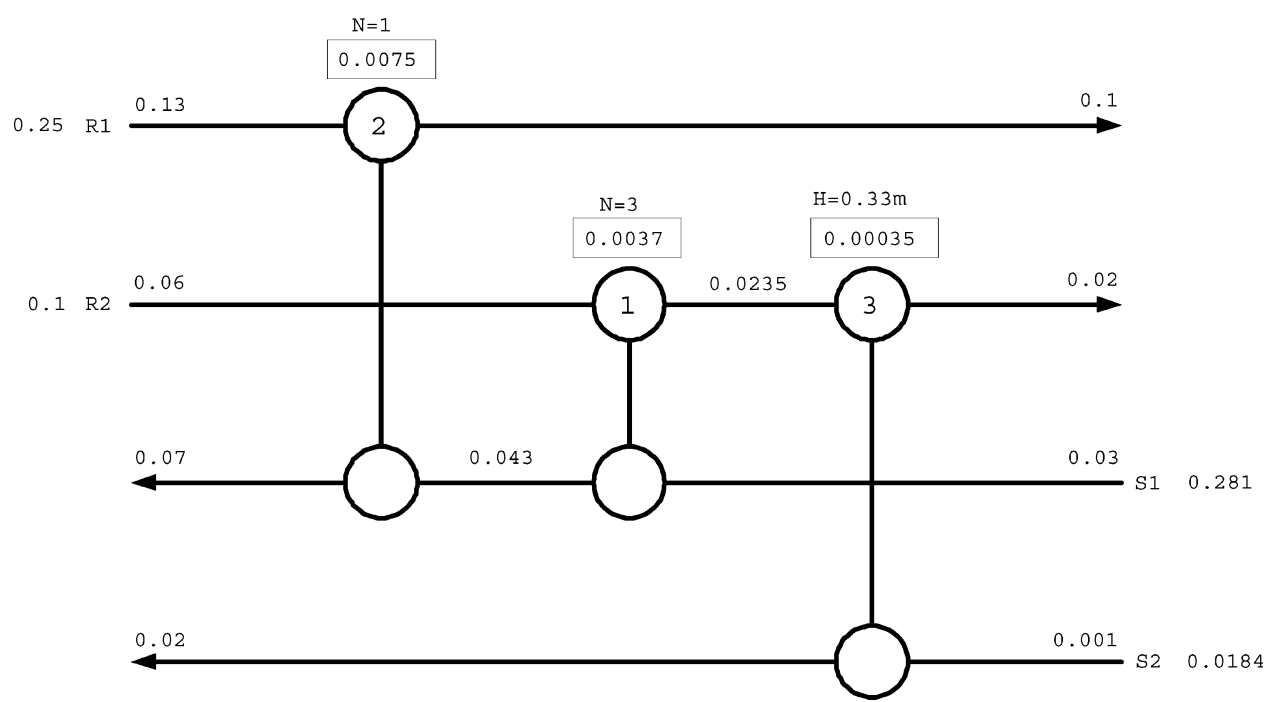

Figure 6. Grass-roots MEN design for copper recovery example by Hallale and Fraser. ${ }^{8}$

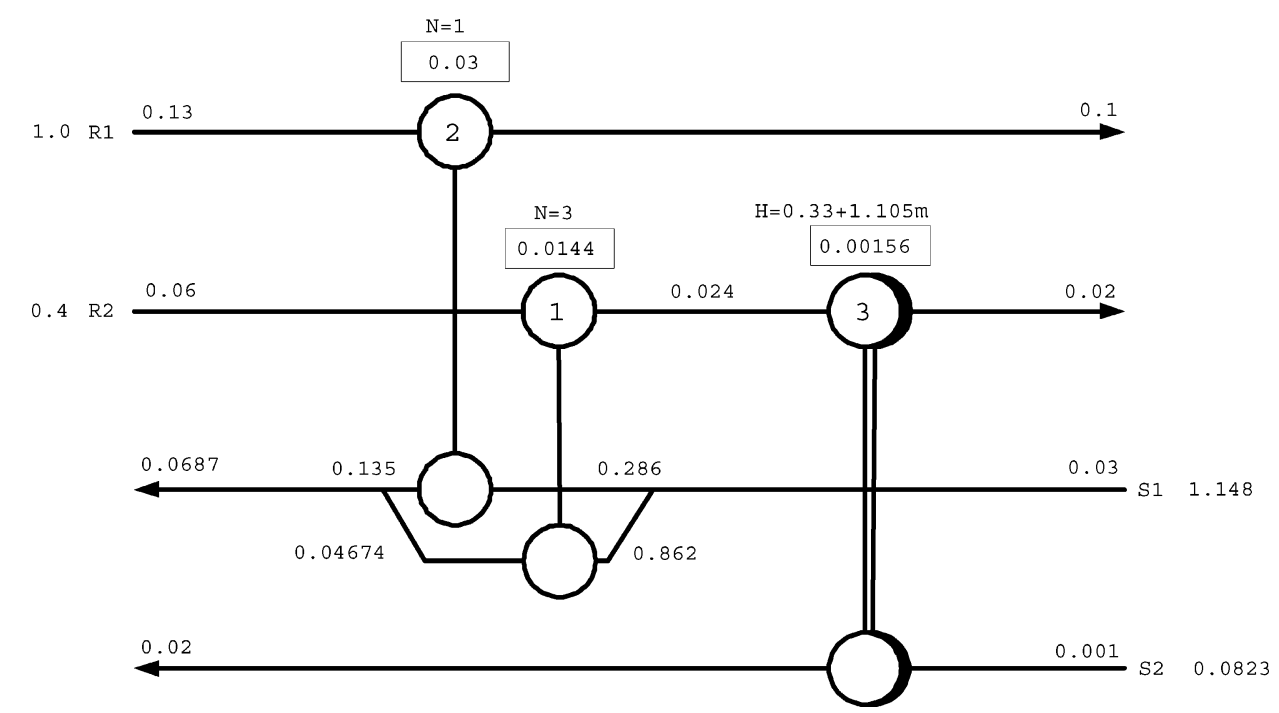

Figure 7. Proposed retrofit design for copper recovery example.

\section{Conclusion}

In this paper, a MINLP model based on the stagewise superstructure representation of mass-exchange networks has been proposed for the retrofit of MENs. This model simultaneously considers the tradeoff between costs for the external mass separating agents, the reassignment of existing units, the cost for additional tray numbers, column heights, or both, and the cost for the installation of new units. Several case studies with single or multiple contaminants, including the coke-oven gas sweetening for the removal of hydrogen sulfide and carbon dioxide and the copper recovery in an etching plant, are used to illustrate the merits of the proposed retrofit model.

\section{Acknowledgment}

Financial support of Ministry of Economic Affairs under grant 92-EC-17-A-09-S1-019 is gratefully acknowledged.

\section{Appendix A. Derivation of Equation 8}

The feasibility constraints of the equilibrium relationships, eq 8, ensure positive driving forces for the potential process exchange units. Binary variables, $z_{i j k}$, are used for these constraints to ensure that only nonnegative driving forces exist for existing matches where the associated binary variables all equal one. If a match is not needed, the associated binary variable would equal zero and the large positive upper bound $\Gamma$ can deem the equation redundant. In these equations, a streams-and-component dependent minimum composition approach, $\epsilon_{i j}^{n}$, is also chosen so that feasible mass transfer in a finite number of equilibrium stages or a finite area can be achieved in each transfer unit. It should be noted that Hallale and Fraser ${ }^{8}$ have pointed out the dangers of using arbitrarily assigned values of the minimum composition approach, which might lead to a significantly poor design. However, this could be done by assigning a very small value to the minimum composition differences for each of the streams, and the optimization technique will exclude large exchangers with driving forces that are too small.

$$
\begin{gathered}
y_{i k}^{n}-m_{i j}^{n}\left(s x_{i j k}^{n}+\epsilon_{i j}^{n}\right)-b_{i j}^{n}+\Gamma\left(1-z_{i j k}\right) \geq 0 \\
\forall i \in \mathbf{R P}, j \in \mathbf{L P}, k \in \mathbf{S T}, n \in \mathbf{T C} \\
s y_{i j k}^{n}-m_{i j}^{n}\left(x_{j, k+1}^{n}+\epsilon_{i j}^{n}\right)-b_{i j}^{n}+\Gamma\left(1-z_{i j k}\right) \geq 0 \\
\forall i \in \mathbf{R P}, j \in \mathbf{L P}, k \in \mathbf{S T}, n \in \mathbf{T C}(\mathrm{A} 1)
\end{gathered}
$$


Equation A1 can be rearranged as follows

$$
\begin{gathered}
y_{i k}^{n}-m_{i j}^{n} s x_{i j k}^{n}-b_{i j}^{n}+\Gamma\left(1-z_{i j k}\right) \geq m_{i j}^{n} \epsilon_{i j}^{n} \\
\forall i \in \mathbf{R P}, j \in \mathbf{L P}, k \in \mathbf{S T}, n \in \mathbf{T C} \\
s y_{i j k}^{n}-m_{i j}^{n} x_{j, k+1}^{n}-b_{i j}^{n}+\Gamma\left(1-z_{i j k}\right) \geq m_{i j}^{n} \epsilon_{i j}^{n} \\
\forall i \in \mathbf{R P}, j \in \mathbf{L P}, k \in \mathbf{S T}, n \in \mathbf{T C}(\mathrm{A} 2)
\end{gathered}
$$

The definition of two new variables, $d y x i_{i j k}^{n}$ and $d y x o_{i j k}^{n}$, for representing the left-hand side of eq A2 results in eq 8

$$
\begin{gathered}
d y x i_{i j k}^{n}, d y x o_{i j k}^{n} \geq m_{i j}^{n} \epsilon_{i j}^{n} \\
\forall i \in \mathbf{R P}, j \in \mathbf{L P}, k \in \mathbf{S T}, n \in \mathbf{T C} \\
d y x i_{i j k}^{n} \leq y_{i k}^{n}-m_{i j}^{n} s x_{i j k}^{n}-b_{i j}^{n}+\Gamma\left(1-z_{i j k}\right) \\
\forall i \in \mathbf{R P}, j \in \mathbf{L P}, k \in \mathbf{S T}, n \in \mathbf{T C} \\
d y x o_{i j k}^{n} \leq s y_{i j k}^{n}-m_{i j}^{n} x_{j, k+1}^{n}-b_{i j}^{n}+\Gamma\left(1-z_{i j k}\right) \\
\forall i \in \mathbf{R P}, j \in \mathbf{L P}, k \in \mathbf{S T}, n \in \mathbf{T C}(8)
\end{gathered}
$$

\section{Appendix B. Sizing Equations for Mass-Transfer Units, Equation 11}

Mass exchangers can be classified into two main categories: the stagewise exchangers and the continuous-contact exchangers. ${ }^{1}$ The most common types of stagewise exchangers are tray or plate columns. When mass exchange takes place in a tray column, the number of required stages can be determined from the Kremser equation. The traditional form for the Kremser equation can be expressed as follows if the operating and equilibrium lines are both straight ${ }^{20,21,24}$

$$
\begin{cases}\frac{\ln \left[\left(\frac{y_{i k}^{n}-y_{i j, k+1}^{n^{*}}}{s y_{i j k}^{n}-y_{i j, k+1}^{n^{*}}}\right)\left(1-\frac{m_{i j}^{n} g_{i j k}}{l_{i j k}}\right)+\frac{m_{i j}^{n} g_{i j k}}{l_{i j k}}\right]}{\ln \left[\frac{l_{i j k}}{m_{i j}^{n} g_{i j k}}\right]} & \text { for } \frac{l_{i j k}}{m_{i j} g_{i j k}} \neq 1 \\ \frac{y_{i k}^{n}-s y_{i j k}^{n}}{s y_{i j k}^{n}-y_{i j, k+1}^{n^{*}}} & \text { for } \frac{l_{i j k}}{m_{i j}^{n} g_{i j k}}=1\end{cases}
$$

Where, $y_{i j, k+1}^{n^{*}}=m_{i j}^{n} x_{j, k+1}^{n}+b_{i j}^{\mathrm{n}}$ and $s y_{i j k}^{n^{*}}=m_{i j}^{n} s x_{i j k}^{\mathrm{n}}+b_{i j}^{\mathrm{n}}$ are equilibrium compositions. The linear equilibrium relationship and the material balance equation can be further substituted into eq B1 to give the following alternative for the Kremser equation ${ }^{21}$

$$
\begin{aligned}
& N \mathrm{st}_{i j k}^{n}= \\
& \begin{cases}\frac{\log \operatorname{mean}\left[y_{i k}^{n}-s y_{i j k}^{n}, s y_{i j k}^{n^{*}}-y_{i j, k+1}^{n^{*}}\right]}{\log \operatorname{mean}\left[y_{i k}^{n}-s y_{i j k}^{n^{*}}, s y_{i j k}^{n}-y_{i j, k+1}^{n^{*}}\right]} & \text { for } \frac{l_{i j k}}{m_{i j}^{n} g_{i j k}} \neq 1 \\
\frac{y_{i k}^{n}-s y_{i j k}^{n}}{y_{i k}^{n}-s y_{i j k}^{n^{*}}}=\frac{y_{i k}^{n}-s y_{i j k}^{n}}{s y_{i j k}^{n}-y_{i j, k+1}^{n^{*}}} & \text { for } \frac{l_{i j k}}{m_{i j}^{n} g_{i j k}}=1\end{cases}
\end{aligned}
$$

Notably the $\log -$ mean Kremser representation for the case of $l_{i j k} / m_{i j}^{n} g_{i j k} \neq 1$ will be equivalent to the second one for the $l_{i j k} / m_{i j}^{n} g_{i j k}=1$ case. However, eq B2 will still lead to numerical difficulties for some zero values in the $\log -$ mean. Thus an approximation for the composition difference term is required to avoid numerical problems when the approach compositions of both sides of the mass exchange unit are equal. ${ }^{21,22,23}$ Here, the Chen's approximation ${ }^{19,21,22}$ is used, as shown in the following

$\log \operatorname{mean}\left[y_{i k n}-s y_{i j k}^{n}, s y_{i j k}^{n^{*}}-y_{i j, k+1}^{n^{*}}\right]=$

$$
\begin{gathered}
\frac{\left(y_{i k}^{n}-s y_{i j k}^{n}\right)-\left(s y_{i j k}^{n^{*}}\right)-\left(s y_{i j k}^{n^{*}}-y_{i j, k+1}^{n^{*}}\right)}{\ln \left[\frac{y_{i k}^{n}-s y_{i j k}^{n}}{s y_{i j k}^{n^{*}}-y_{i j, k+1}^{n^{*}}}\right]} \cong \\
{\left[\frac{\left(y_{i k}^{n}-s y_{i j k}^{n}\right)^{0.3275}+\left(s y_{i j k}^{n^{*}}-y_{i j, k+1}^{n^{*}}\right)^{0.3275}}{2}\right]^{1 / 0.3275}}
\end{gathered}
$$

Thus the log-mean Kremser equation for stage numbers, eq B2, can be reformulated as follows

$$
\begin{aligned}
& N s t_{i j k}^{n} \simeq\left[\frac{\left(y_{i k}^{n}-s y_{i j k}^{n}\right)^{0.3275}+\left(s y_{i j k}^{n^{*}}-y_{i j, k+1}^{n^{*}}\right)^{0.3275}}{\left(y_{i k}^{n}-s y_{i j k}^{n^{*}}\right)^{0.3275}+\left(s y_{i j k}^{n}-y_{i j, k+1}\right)^{0.3275}}\right]^{1 / 0.3275} \\
&= {\left[\frac{\left(y_{i k}^{n}-s y_{i j k}^{n}\right)^{0.3275}+\left(s y_{i j k}^{n^{*}}-y_{i j, k+1}^{n^{*}}\right)^{0.3275}}{\left(d y i_{i j k}^{n}\right)^{0.3275}+\left(d y x o_{i j, k+1}^{n}\right)^{0.3275}}\right]^{1 / 0.3275} } \\
& \forall \frac{l_{i j k}}{m_{i j}^{n} g_{i j k}}(\mathrm{~B} 4
\end{aligned}
$$

When absorption or stripping takes place, a continuous-contact packed tower is suggested for mass exchange. The required packed height for $(i, j)$ match in stage $k$ for separation of component $n, H_{i j k}^{n}$, is characterized by a number of imaginary transfer units, $\mathrm{NTU}_{i j k}^{n}$, and the overall height of a transfer unit, HTU $_{i j k}^{n}{ }^{n}{ }^{6,24}$ Therein, calculations are based on the conditions in the rich stream. The overall packed height is given by the following equation, where the $\log -$ mean calculation is also applying Chen's approximation. ${ }^{19,21,22}$

$$
\begin{aligned}
\mathrm{HTU}_{i j k}^{n} & =\frac{g_{i j k}}{K_{y}^{n} a S} \\
\mathrm{NTU}_{i j k}^{n} & =\frac{y_{i k}^{n}-s y_{i j k}^{n}}{\log \operatorname{mean}\left[y_{i k}^{n}-s y_{i j k}^{n}, s y_{i j k}^{n}-y_{i j, k+1}^{n} *\right]} \\
H_{i j k}^{n} & =\mathrm{HTU}_{i j k}^{n} \times \mathrm{NTU}_{i j k}^{n} \\
& =\frac{M_{i j k}^{n}}{K_{y}^{n} a S \log \operatorname{mean}\left[y_{i k}^{n}-s y_{i j k}^{n}, s y_{i j k}^{n}-y_{i j, k+1}^{n} *\right]} \\
& =\frac{M_{i j k}^{n}}{K_{y}^{n} a S\left[\frac{\left(y_{i k}^{n}-s y_{i j k}^{n}\right)^{0.3275}+\left(s y_{i j k}^{n}-y_{i j, k+1}^{n}\right)^{0.3275}}{2}\right]^{1 / 0.3275}} \\
& =\frac{M_{i j k}^{n}}{K_{y}^{n} a S\left[\frac{\left(d y x i_{i j k}^{n}\right)^{0.3275}+\left(d y x x_{i j k}^{n}\right)^{0.3275}}{2}\right]^{1 / 0.3275}}
\end{aligned}
$$

\section{Nomenclature}

\section{Indices}

$i=$ rich process stream in retrofit network

$j=$ lean process stream or mass separation agent (MSA) in retrofit network

$k=$ index for stage, $1, \ldots, N_{\mathrm{S}}$, and concentration location, $1, \ldots, N_{\mathrm{S}}+1$ in retrofit network

$n=$ transferable component

$o=$ rich process stream in existing network 
$p=$ lean process stream or mass separation agent (MSA) in existing network

$q=$ index for stage and concentration location in existing network

Sets

$\mathbf{R P}=\{i \mid i$ is a rich process stream in retrofit network, $i=$ $\left.1, \ldots, N_{\mathrm{R}}\right\}$

$\mathbf{L P}=\{j \mid j$ is a lean process stream or MSA in retrofit network, $\left.\mathrm{j}=1, \ldots, N_{\mathrm{L}}\right\}$

$\mathbf{L P}(\mathrm{t})=\{j \mid j$ is a lean process stream or MSA using tray column $\}$

$\mathbf{L P}(\mathrm{h})=\{j \mid j$ is a lean process stream or MSA using packed column\}

$\mathbf{T C}=\left\{n \mid n\right.$ is a transferable component, $\left.\mathrm{n}=1, \ldots, N_{\mathrm{C}}\right\}$

$\mathbf{S T}=\left\{k \mid k\right.$ is a stage in retrofit network, $\left.\mathrm{k}=1, \ldots, N_{\mathrm{S}}\right\}$

$E_{p}=\{(o, p, q) \mid(o, p, q)$ corresponds to an existing match for rich stream $o$ and lean stream $p$ at stage $q$ \}

Parameters

$\mathrm{AC}_{j}=$ annual operating cost of lean stream $j$

$\mathrm{CAF}=$ Capital annualization factor

$b_{i j}^{n}=$ intercept of equilibrium line for component $n$ in $i$ rich and $j$ lean match

$C_{i j k}^{o p q}=$ fixed reassignment cost of exchange unit from $(o, p$, $q)$ to $(i, j, k)$

$C_{i j k}^{(\text {inst })}=$ fixed installation cost of a new exchange unit

$C_{i j k}^{(\mathrm{t})}=$ per stage cost of tray column

$C_{i j k}^{(\mathrm{h})}=$ unit height cost of packed tower

$G_{i}=$ flow rate of rich stream $i$

$K_{y}^{n} a=$ overall mass transfer coefficient for component $n$

$L_{j}^{\text {(up) }}=$ upper bound on mass flow rate of lean stream $j$

$m_{i j}^{n}=$ slope of equilibrium line for component $n$ in $i$ rich and $j$ lean match

$S=$ cross-sectional area of an exchange unit

$U=$ upper bound for mass exchanged

$\Gamma=$ upper bound for composition difference

$X_{j}^{n(\mathrm{in})}=$ inlet composition of lean stream $j$ for component $n$

$X_{j}^{n(\text { out })}=$ outlet composition of lean stream $j$ for component $n$

$X_{j}^{n(\text { up) }}=$ upper bound composition of lean stream $j$ for component $n$

$Y_{i}^{n(\text { up })}=$ inlet composition of rich stream $i$ for component $n$

$Y_{i}^{n \text { (out) }}=$ outlet composition of rich stream $i$ for component $n$

$Y_{i}^{n \text { (out) }}=$ upper bound composition of rich stream $i$ for component $n$

$\epsilon_{i j}^{n}=$ minimum composition difference for component $n$ between rich stream $i$ and lean stream $j$

Variables

$d y x i_{i j k}^{n}=$ composition approach in the lean end of the mass exchanger between rich $i$ and lean $j$ in stage $k$

$d y x o_{i j k}^{n}=$ composition approach in the rich end of the mass exchanger between rich $i$ and lean $j$ in stage $k$

$N_{i j k}=$ number of trays in the tray column $(i, j, k)$ in retrofit network

$N_{i j k}^{(\text {reassign })}=$ number of trays reassigned to unit $(i, j, k)$ from an existing unit

$N_{i j k}^{(\text {add })}=$ additional number of trays required for unit $(i, j$, $k$ ) in retrofit network

$N_{o p q}^{(\text {exist })}=$ number of trays for existing perforated column $(o, p, q)$

$H_{i j k}=$ height of the packed column $(i, j, k)$ in retrofit network

$H_{i j k}^{(\text {reassign })}=$ column height reassigned to unit $(i, j, k)$ from an existing unit
$H_{i j k}^{(\text {add })}=$ column height required for unit $(i, j, k)$ in retrofit network

$H_{o p q}^{(\text {exist })}=$ column height for existing packed tower $(o, p, q)$

HTU $=$ height of an overall rich-phase transfer unit

NTU $=$ number of overall rich-phase transfer units

$g_{i j k}=$ flow rate of rich $i$ that is connected to lean $j$ in stage $k$

$l_{i j k}=$ flow rate of lean $j$ that is connected to rich $i$ in stage $k$

$L_{j}=$ flow rate of lean process stream $j$

$M_{i j k}^{n}=$ mass exchanged for component $n$ between rich stream $i$ and lean stream $j$ in stage $k$

$s x_{i j k}^{n}=$ composition of $n$ for the part of lean $j$ that is connected to rich $i$ in the rich end of an exchanger in stage $k$

$s y_{i j k}^{n}=$ composition of $n$ for the part of rich $i$ that is connected to lean $j$ in the lean end of an exchanger in stage $k$

$x_{j k}^{n}=$ composition of $n$ for lean stream $j$ at composition location $k$

$y_{i k}^{n}=$ composition of $n$ for rich stream $i$ at composition location $k$

$z_{i j k}=$ denoting existence of process match $(i, j)$ in stage $k$ $z_{i j k}^{\text {(new) }}=$ new process match $(i, j, k)$ in retrofit network

$w_{i j k}^{o p q}=$ denoting reassignment of existing process match $(o, p, q)$ to new process match $(i, j, k)$

Note Added after ASAP Publication. The version of this paper that was published on the Web 7/30/05 contained minor errors involving eqs $5,8,11$, and 19 in the text and some of the equations in the Appendices, as well as an entry in the Nomenclature section. The correct version of the paper was posted to the Web 8/12/ 05 .

\section{Literature Cited}

(1) Hallale, N. Mass Transfer Technology for Pollution Prevention. In Process Design Tools for the Environment; Sikdar, S. S., El-Halwagi, M. M, Eds.; Taylor \& Francis: London, 2001; Chapter 7.

(2) El-Halwagi, M. M.; Manousiouthakis, V. Synthesis of Mass Exchange Networks. AIChE J. 1989, 35, 1233.

(3) El-Halwagi, M. M.; Manousiouthakis, V. Automatic Synthesis of Mass Exchange Networks with Single Component Targets. Chem. Eng. Sci. 1990, 45, 2813.

(4) El-Halwagi, M. M.; Manousiouthakis, V. Simultaneous Synthesis of Mass-Exchange and Regeneration Networks. AIChE J. 1990, 36, 1209.

(5) Hallale, N.; Fraser, D. M. Capital and Total Cost Targets for Mass Exchange Networks. Part 1: Simple Capital Cost Models. Comput. Chem. Eng. 2000, 23, 1661.

(6) Hallale, N.; Fraser, D. M. Capital and Total Cost Targets for Mass Exchange Networks. Part 2: Detailed Capital Cost Models. Comput. Chem. Eng. 2000, 23, 1681.

(7) Hallale, N.; Fraser, D. M. Supertargeting for Mass Exchange Networks Part I: Targeting and Design Techniques. Trans. IChemE. 2000, 78, 202.

(8) Hallale, N.; Fraser, D. M. Supertargeting for Mass Exchange Networks Part II: Applications. Trans. IChemE. 2000, 78, 208.

(9) Papalexandri, K. P.; Pistikopoulos, E. N.; Floudas, C. A. Mass Exchange Networks for Waste Minimization: A Simultaneous Approach. Trans. IChemE. 1994, 72, 279.

(10) Fraser, D. M.; Hallale, N. Retrofit of Mass Exchange Networks Using Pinch Technology. AIChE J. 2000, 46, 2112.

(11) Tjoe, T. N.; Linnhoff, B. Using Pinch Technology for Process Retrofit. Chem. Eng. 1986, 93, 47.

(12) Ciric, A. R.; Floudas, C. A. A Mixed Integer Nonlinear Programming Model for Retrofitting Heat Exchanger Networks. Ind. Eng. Chem. Res. 1990, 29, 239. 
(13) Yee, T. F.; Grossmann, I. E. A Screening and Optimization Approach for the Retrofit of Heat Exchanger Networks. Ind. Eng. Chem. Res. 1991, 30, 146.

(14) Ma, K. L.; Hui, C. W.; Yee, T. F. Constant Approach Temperature Model for HEN Retrofit. Appl. Therm. Eng. 2000, 20, 1505.

(15) Szitkai, Z.; Farkas, T.; Kravanja, Z.; Lelkes, Z.; Rev, E.; Fonyo, Z. A New MINLP Model for Mass Exchange Network Synthesis. In Proceedings of ESCAPE-13, Lappeenranta, Finland 1-4 June, 2003; Kraslawski, V. A., Turunen, I., Eds.; Elsevier: Amsterdam, 2003; Vol. 14, pp 323-328.

(16) Chen, C. L.; Hung, P. S. Simultaneous Synthesis of Mass Exchange Networks for Waste Minimization. Comput. Chem. Eng. 2005, 29, 1516 .

(17) Bjork, K. M.; Westerlund, T. Global Optimization of Heat Exchanger Network Synthesis Problems With and Without the Isothermal Mixing Assumption. Comput. Chem. Eng. 2002, 26, 1581.

(18) Brooke, A.; Kendrick, D.; Meeraus, A.; Raman, R.; Rosenthal, R. E. GMAS: A User's Guide; Scientific Press: Redwood City, CA. 1998.

(19) Chen, J. J. J. Letter to the Editor: Comments on Improvement on A Replacement for the Logarithmic Mean. Chem. Eng. Sci. 1987, 42, 2488.
(20) Szitkai, Z.; Lelkes Z.; Rev, E.; Fonyo, Z. Handling of Removable Discontinuities in MINLP Models for Process Synthesis Problems, Formulations of the Kremser Equation. Comput. Chem. Eng. 2002, 26, 1501.

(21) Shenoy, U. V.; Fraser, D. M. A New Formulation of the Kremser Equation for Sizing Mass Exchangers. Chem. Eng. Sci. 2003, 58,5121 .

(22) Yee, T. F.; Grossmann, I. E. Simultaneous Optimization Models for Heat Integration I. Area and Energy Targeting and Modeling of Multi-Stream Exchangers. Comput. Chem. Eng. 1990, 14,1151 .

(23) Yee, T. F.; Grossmann, I. E. Simultaneous Optimization Models for Heat Integration II. Heat Exchanger Network Synthesis. Comput. Chem. Eng. 1990, 14, 1165.

(24) Treybal, R. E. Mass Transfer Operations, 3rd ed.; McGrawHill: Singapore, 1981.

Received for review December 6, 2004 Revised manuscript received June 14, 2005 Accepted June 27, 2005

IE048819Z 